The NICHD Protocol: A review of an internationally-used evidence-based tool for training child forensic interviewers

David La Rooy ${ }^{\mathrm{a}}$, Sonja P. Brubacher ${ }^{\mathrm{b}}$, Anu Aromäki-Stratos ${ }^{\mathrm{c}}$, Mireille Cyr $^{\mathrm{d}}$, Irit Hershkowitz ${ }^{\mathrm{e}}$, Julia Korkman ${ }^{\mathrm{f}}$, Trond Myklebust ${ }^{\mathrm{g}}$, Makiko Naka ${ }^{\mathrm{h}}$, Carlos E. Peixoto ${ }^{\mathrm{i}}$, Kim P. Roberts ${ }^{\mathrm{j}}$, Heather Stewart ${ }^{\mathrm{k}} \&$ Michael E. Lamb ${ }^{1}$

${ }^{a}$ Abertay University \& Scottish Institute for Policing Research, Dundee Scotland, UK.

${ }^{\mathrm{b}}$ Banting Postdoctoral Fellow, Department of Psychology, Central Michigan University, $1200 \mathrm{~S}$. Franklin St. Mount Pleasant, MI, 48859, USA

${ }^{c}$ Forensic Psychiatry Unit for Children and Adolescents, Intermunicipal Hospital District of Southwest Finland, Turku, Finland

${ }^{d}$ Département de psychologie, Université de Montréal, C.P. 6128, Succursale Centre-Ville, Montréal, Québec, Canada, H3C 3J7

e University of Haifa, Israel

f Åbo Akademi University \& Helsinki University Hospital, Finland

g Norwegian Police University College, Research Department, Norway

${ }^{\mathrm{h}}$ Department of Psychology, Hokkaido University, Japan

I Psicólogo Forense, Forensic Psychologist, Portugal

j Department of Psychology, Wilfrid Laurier University, 75 University Ave W, Waterloo, ON, N2L 3C5

${ }^{k}$ Avenues Children's Justice Center, 257 11th Avenue, Salt Lake City, Utah 84103

${ }^{1}$ Department of Psychology, University of Cambridge, Free School Lane, Cambridge CB2 3RQ, UK.

Author Note: Correspondence: Dr David La Rooy (david@larooy.net). The structure of this article was determined by David La Rooy, Sonja Brubacher and Michael E. Lamb; all other contributors are listed alphabetically. 


\begin{abstract}
This article reviews an evidence-based tool for training child forensic interviewers called the NICHD Protocol, and the relevant research on: children's memory development; communication; suggestibility; the importance of open-prompts, and challenges associated with interview training. We include international contributions from experienced trainers, practitioners, and scientists, who are already using the Protocol or whose national or regional procedures have been directly influenced by the NICHD Protocol research (Canada, Finland, Israel, Japan, Korea, Norway, Portugal, Scotland, and United States). Throughout the review, these experts comment on: how and when the Protocol was adopted in their country; who uses it; challenges to implementation and translation; training procedures; and other pertinent aspects. We aim to further promote good interviewing practice by sharing the experiences of these experts. The NICHD Protocol can be easily incorporated into existing training programs worldwide and is available for free. It was originally developed in English and Hebrew and is available in several other languages at nichdprotocol.com.
\end{abstract}

Keywords: NICHD Protocol; child sexual abuse; forensic interviews, Evidence Based Investigative Interviewing 


\section{The NICHD Protocol: A review of an internationally-used evidence-based tool for training child forensic interviewers}

For legal reasons, those involved in the area of child forensic interviewing must be knowledgeable about research underlying children's development and the procedures that have emerged from that knowledge base, making clear how best to train and advise those tasked with the frontline duty of eliciting high-quality information from alleged victims of child abuse. In this article, we describe the evidence base, development, and structure of a training tool known as the NICHD Protocol (the National Institute of Child Health and Human Development Protocol). This training tool was developed through the intensive efforts of US Government Scientists at the National Institutes of Health in the 1990s in collaboration with a wide range of professionals including lawyers, developmental and clinical psychologists, law enforcement, and behavioural scientists, especially in the USA and Israel. Importantly, it has been the subject of intensive evaluation and research that is reviewed in the book Tell me what happened by Lamb, Hershkowitz, Orbach and Esplin (2008).

Central to the development of interview guidelines has been knowledge of how memory works, children's developmental capabilities, and the conditions that improve children's ability to discuss their abuse experiences. After many decades of experimental and applied memory research, conducted primarily by psychologists, we have come to understand the strengths, weaknesses, and features of children's memory very well, and this knowledge has shaped many professional recommendations about interviewing children (e.g., American Professional Society on the Abuse of Children [APSAC], 1990, 1997; Home Office, 1992, 2002, 2007, Lamb, Orbach, Hershkowitz, Esplin, \& Horowitz, 2007; Ministry of Justice, 2011; Poole \& Lamb, 
1998; Scottish Executive, 2003, 2011). Because our knowledge of memory is now so advanced, core recommendations made by professional bodies worldwide share remarkable consensus (Lamb et al., 2007; Lamb, La Rooy, Malloy, \& Katz, 2011). Small differences in recommended procedures usually arise out of regional idiosyncratic legal constraints, rather than disagreements between scientists about the basic nature of memory and children's developing abilities. While structured, the NICHD Protocol is flexible enough to allow for such modifications to enhance its applicability for use around the world. We now briefly review the empirical literature on children's memory development that served to guide all aspects of the NICHD Protocol.

\section{Important Characteristics of Memory Development}

Very young children can remember and report their experiences. It is paradoxical that, as adults, we have very little recollection of our early years of life, whereas young children and infants can and do remember their experiences, at least for a short period of time (e.g., Bauer, Wenner, Dropik, \& Wewerka, 2000). Memory for experiences in fact develops long before infants can tell us about them verbally (Hayne, 2004). For example, infants have been shown to remember how to make a crib mobile move (by kicking) when tested days later. By 3 years of age children can recall experiences for increasingly longer periods of time (e.g., Bruck, Ceci, Francouer, \& Renick, 1995; Fivush, Gray, \& Fromhoff, 1987; Quas \& Schaaf, 2002), but are likely to have forgotten the incidents by adulthood (see Peterson, 2012, for a review). This phenomenon has been termed 'infantile amnesia' and has been demonstrated in many studies (Peterson, 2012).

Quas, Goodman, Bidrose, Pipe, Craw and Ablin (1999) tested children's memory for invasive medical procedures that occurred when the children were between 2 and 7 years of age. The procedure (Voiding Cystourethrogram, or VCUG) involves taking X-rays while children 
urinate to identify potential kidney problems and infections. In the study, children were interviewed one to five years after experiencing this procedure (children interviewed at shorter delays tended to recall more details of the experience, but delay did not significantly affect inaccuracies). Although the procedure involved invasive genital contact and was quite distressing for most children, those who had the procedure when they were 2 and 3 years old had little to no memory for the experience, in contrast to nearly all children 5 to 7 years old. Taken together, the implications of these findings are that older children and adults are highly unlikely to remember detailed events that occurred prior to age 3 . When older children and adults do claim to remember early events, there is a real possibility that they have reconstructed/imagined what 'might' have happened based on conversations with others (e.g., parents), interviewer and therapist suggestions, photographs, or from vague memories that have been reinterpreted over time and mixed with their current knowledge and beliefs (see Goodman, Pipe, \& McWilliams, 2011; Loftus, 2005; Pezdek \& Lam, 2007, for reviews. Indeed, one of us recalls several instances when his young daughter injured herself badly enough to require stitches, but today her only recollection of these events is based upon conversations with her father, rather than her own independent memories.

Researchers studying the event memory of preschool- and school-aged children usually 'stage' events about which the children are questioned sometime later. Because the events in question are documented in detail, it is possible to compare what children recall about the event to what actually happened and determine the accuracy of memory. A variety of events have been employed using this basic procedure including stressful events (e.g., painful medical procedures or emergencies, vaccinations, and natural disasters), pediatric examinations during which children are touched by a doctor as part of the routine examination, and interactive events in 
which children participate in or 'witness' a series of activities (e.g., play sessions, magic shows, pirate shows, science demonstrations). In other studies, children see short films or video presentations about which they are later questioned (see La Rooy, Malloy, \& Lamb, 2011; Peterson, 2002; Segovia \& Crossman, 2012, for reviews). The results of these studies demonstrate clear developmental improvements in the ability to remember events and to retain them for longer periods of time. Nevertheless, while children can have impressive and accurate memories for their experiences, these memories can be fragile and thus vulnerable to contamination, which we discuss in the next section. For that reason, the 'best' interviewing techniques impose as minimally as possible on children's accounts.

\section{Children's accounts can become contaminated when they are interviewed}

inappropriately. In the 80 s and 90 s high-profile child-abuse cases, such as the McMartin preschool and Kelly Michaels case in the United States (Ceci \& Bruck, 1995; Garven, Wood, Malpass, \& Shaw, 1998; Myers, 2009), the Orkney inquiries in Scotland (Black, 1992; Clyde, 1992), the Peter Ellis case in New Zealand (Hood, 2002) among others, sparked concerns throughout the psychological and legal worlds about the suggestive ways in which children were interviewed. In many of these cases, suggestive interviews yielded false allegations that children had been raped, genitally penetrated with knives, forced to consume feces, buried alive, transported through underground tunnels, and witnessed murders, all during normal working hours when parents were free to come and go as they pleased from the day care centre. Nowadays it may seem obvious that the ways children are interviewed can foster false allegations, but in the past, widely-held but erroneous beliefs about children's memories were fuelled by social hysteria and untested diagnostic therapies that seemed to 'prove' the 'widespread' nature of the problem (e.g., Bass \& Davis, 1988). 
An often-cited study illustrating how susceptible memory is to distortion was conducted by Leichtman and Ceci (1995). A children's daycare was visited during story time by 'Sam Stone' who commented on the story (saying it was one of his favourites), walked about the classroom and then waved goodbye and left. The children were interviewed about the visit once a week for 5 weeks. Some were interviewed in a neutral manner and some were interviewed suggestively. In addition, half of the children were told that Sam Stone was clumsy (a negative stereotype) prior to his classroom visit. The suggestive interviewing involved showing children a ripped book and a soiled teddy as evidence of 'bad deeds' by Sam Stone. In the final interviews all children were asked, "did you see him...[rip the book/soil the teddy] with your own eyes?" When children were interviewed non-suggestively almost no children made claims about the 'bad deeds' whether or not the negative stereotype (i.e., clumsiness) had been introduced beforehand. However, the combination of suggestive interviewing and negative stereotyping led $30 \%$ of the 5- to 6-year-olds and $46 \%$ of the 3 - to 4 -year-olds to agree that they had seen Sam rip the book or soil the teddy.

Our understanding of children's suggestibility and false memory (and the danger of therapist 'interventions') is very advanced (e.g., Brainerd \& Reyna, 2005; Ridley, Gabbert \& La Rooy, 2013). We now know from experimental research that poor interviewing in the form of delivering misleading information (with or without props; once or repeatedly; with or without the presence of social or peer pressure, etc.) can lead children to report inaccuracies (e.g., Ceci, Kulkofsky, Klemfuss, Sweeney \& Bruck, 2007).

The results of poorly conducted interviews clearly have terrible consequences. Children are put through lengthy legal and stressful proceedings only to have experts later testify that the interviews were inconclusive. Children who have been abused and are then interviewed poorly 
do not receive appropriate justice. Misunderstandings and inaccuracies may lead to false conviction or family breakup. Children who have been abused may also be sometimes returned to their abusers and be abused again. Abusers may be able to exploit other children. In addition, interviewers are wasting their time, as well as that of the other professionals whose work is impeded by the poor quality of their investigative interviews. Thus, modern interviewing guidelines, such as the NICHD Protocol, were designed to provide interviewers with an evident structure, guiding them through each phase of the interview and helping to avoid poor questioning strategies that may lead to contamination or memory distortions (Lamb et al., 2007).

The importance of using 'open prompts'. Rather than conducting interviews in which information (accurate or inaccurate) is 'delivered' to children, research suggests that children will be much more accurate when information is 'elicited' from free-recall memory (see Orbach \& Pipe, 2011). Free recall memories are accessed in conditions where there is no specific memory cue provided for the child to respond to. For example, the open-ended prompt 'tell me what happened' does not constrain the memory search to a particular topic, but rather allows the child to retrieve memories that are most accessible.

It is important that interviewers understand the 'rule' that helps to decide whether or not interviewer prompts are indeed open. From a practical perspective it can be understood in the following way: Think about the possible answers to the question that has been asked; if the answer can be provided using more than just a few words then it is likely that an open-prompt has been delivered. Questions that only require a few words are closed and/or focused, and do not necessarily tap free-recall memory (Myklebust \& Bjørklund, 2006; Poole \& Lamb, 1998). Instead, focused questions access 'cued' memory. For example, "Was the touch over or under 
your clothes?" , requires the interviewee to select between specified alternatives and is not considered an open prompt.

Closed/focused questions restrict possible responses and increase the risk of inaccuracy because interviewees may choose one of the options even if they cannot recognize the correct answer. What, when, where and how ('specific') type questions may appear 'open,' especially as they seem to be technically non-suggestive, but often only require a few words to answer, and still signify the type of information expected from the child even if an exact response was not specified (e.g., "what colour was the car?"). They are most effective when used to ask for more details about something the interviewee has already mentioned, but they nonetheless can sometimes cause inaccuracy and misunderstanding. For example, in one reported case study an interviewee, when asked what colour the car was, provided the colour of the interior rather than exterior of the car (Jones \& Krugman, 1986); a better question would have been to ask "what colour was the outside of the car?". These types of questions do elicit useful clarifying details but can lead to misunderstanding if they are not carefully composed.

It is well-understood that children answer closed and specific questions less accurately than those that are open-ended. For example in an early study, Dent and Stephenson (1979) showed 10- and 11-year-old children a short film of a theft, capture, escape and ensuing chase of the offender. They compared the accuracy of answers to questions about the event and found that the children were $91 \%$ accurate when responding to open prompts but only $81 \%$ accurate when answering closed/specific questions. In a case study examining information obtained from a 5year-old girl using open and closed prompts, Orbach and Lamb (2001) found that 90\% of the contradictory details this alleged victim provided were elicited using closed/specific questions and suggestive questions whereas no contradictions came in response to open-ended prompts. 
Such dramatic differences in the quality of information elicited using different types of questions explains why interview guidelines universally emphasize the importance of eliciting as much information as possible using open-ended prompts.

Thus, because open prompts tap free-recall memory, interviewers who use them are at an advantage because the information that they obtain is likely to be more accurate irrespective of age, and they elicit longer and more detailed responses than closed and specific questions. Because open-prompts are less likely to contain suggested information, defence counsel are far less able to criticise an interviewer for obtaining information through open-ended prompting.

The verbal competence of the children is not only important for the interviewers, it also has an effect on the process of cases in court. The decisions in court are affected by the length of the children`s responses in their testimonies (Myklebust \& Bjørklund, 2009), demonstrating the importance of open questions, free narratives, and the use of a structured approach, such as the NICHD protocol.

\section{Forensic interviewing research}

Even though open-ended prompts have been shown to be most effective in eliciting longer, more detailed, and more accurate responses, researchers have repeatedly shown that the recommendation to elicit information from children using open-prompts is routinely not followed by forensic interviewers when they do not have a structured protocol to follow. Studies of interviewing practice in various parts of the United States, United Kingdom, Canada, Sweden, Scotland, Finland, Norway, and Israel consistently show that forensic interviewers use openended prompts quite rarely (e.g. Cederborg, La Rooy \& Lamb, 2008; Korkman, Santtila, \& Sandnabba, 2006; Lamb et al., 1996; Lamb et al., 2009; La Rooy, Lamb \& Memon, 2011; Myklebust \& Bjorklund, 2006; Sternberg, Lamb, Davies, \& Westcott, 2001). 
What is alarming from a service perspective is that, in many studies, considerable expense and effort was directed to training interviewers, the interviewers seem to be well-aware of the recommended practices, and often believed that they were adhering to those recommendations. Research has thus revealed a disturbing dichotomy between 'knowledge about desirable practices' and 'the actual behavior of forensic investigators' (Lamb, Hershkowitz, Orbach, \& Esplin, 2008). In sum, interviewers often 'know' what they should do in theory, but are unable to translate the theory into practice.

We acknowledge that it is difficult for those working as trainers in law enforcement and social services to conceptualize that these traditional training courses used in many countries to promote good interviewer practices have not resulted in significantly better interviewing. Because it is quite easy to raise awareness of best practice principles, it is hard to imagine that best practice would not be adhered to and that traditional 'one-off' training courses change actual interviewing behavior very little (Aldridge \& Cameron, 1999; Stevenson, Leung, \& Cheung, 1992; Warren et al., 1999). Simply put - if people have knowledge and understanding of good practice, why would they not actually put it into practice? The answer, it seems, is that while it is relatively easy to conceptualize good interviewing practice and 'tell' interviewers what they should do, such guidelines do not translate automatically into practice. Research shows that interviewers require a substantial amount of regular support and feedback about the quality of their interviews for improvements in quality to be achieved and maintained (Lamb, Sternberg, Orbach, Esplin, \& Mitchell, 2002a; Lamb, Sternberg, Orbach, Hershkowitz, Horowitz \& Esplin, 2002b).

"Until the year 2003, Finnish child investigative interviews were not regulated, and children were oftentimes 'interviewed' repeatedly [and of questionable quality] within the framework of psychiatric care, without the police being involved and often without the child 
interview being recorded. During that time, it was also fairly commonly believed that child abuse could be "diagnosed", as was the case in many other countries. Studies of interviews conducted prior to 2003 in Finland showed interviews were of poor quality both in terms of being leading and of not being suited to the developmental abilities of children (Korkman, Santtila, Drzewiecki \& Sandnabba, 2008; Korkman, Santtila \& Sandnabba, 2006; Korkman, Santtila, Westeråker \& Sandnabba, 2008; Santtila, Korkman \& Sandnabba, 2004). National guidelines, introduced in 2003 (Taskinen, 2003), emphasized the need for all CSA suspicions to be reported to the police and their investigations to be police-led and properly conducted." - Julia Korkman \& Anu Aromäki-Stratos, Finland

"Since the 1990s, initially inspired by studies by Loftus and colleagues, increasing numbers of Japanese psychologists engaged with the literature on eyewitness memory and suggestibility along with colleagues elsewhere in the world (see Naka, 2006 for review). In 2000, the Japanese Society for Law and Psychology was established and psychologists began to increasingly work with lawyers and in forensic contexts. In these contexts, psychologists saw first-hand the effects of poor quality interviews and the harm that could be caused for both the defendant and child witness. Initially energy was focused on examining and publicizing the inadequacy of poor quality interviews by identifying potentially problematic closed questions, leading questions, repetitive questions, and social pressure and suggestive techniques. As is the case in many other jurisdictions, criticism alone from psychologists does not improve the quality of interviews that are conducted. At the same time in Japan, the number of referrals to Child Guidance Centers doubled, and then tripled, after the Prevention of Child Abuse Act was legislated in 2000 (Gido Gyakutai no Boushitou ni kansuru Houritsu.)'” - Makiko Naka, Japan

\section{An evidence based solution to improve interviewing standards: The NICHD Protocol}

The NICHD Protocol was developed in the mid-1990s to address shortcomings in the quality of interviews that were being conducted. It was created with input from a wide range of professionals including lawyers, developmental, clinical and forensic psychologists, police officers, and social workers, and has been the focus of intensive forensic evaluation and research ever since (see Bull, 2010; Lamb et al., 2008; Saywitz, Lyon, \& Goodman, 2011) and is now widely used internationally.

"The interest in the NICHD Protocol started in Quebec (Canada) in 2000, when professionals from Child-Protective Services (CPS) were looking for new strategies to help them conduct interviews with alleged victims of child sexual abuse. With the agreement of Michael Lamb and his colleagues, we translated the NICHD Protocol into French and tested its effectiveness to modify interviewers' behaviors during investigative interviews. The objective of the study was to compare pre-Protocol interviews with NICHD Protocol interviews conducted by the same interviewers, before and after the training, on the type of questions used by the CPS workers and the number of details obtained from the child. In 2003, the same study was 
proposed to police officers. In both studies (see Cyr \& Lamb, 2009), results showed that the NICHD Protocol was effective in increasing the number of open-ended questions, as well as the number of details obtained from these questions. " - Mireille Cyr, Canada

"A study with child protection workers in Ottawa (Canada's capital city), showed how useful a NICHD-based interview protocol could be. Despite having different aims to investigative interviews, child protection interviewers used a modified NICHD Protocol and subsequently increased the amount of information elicited from children at-risk (Price \& Roberts, 2011; Rischke, Roberts, \& Price, 2011). These workers have to cover a set of issues with children (e.g., use of alcohol in the home, whether children are taken to school) and so we modified the Protocol so that in the first half of the interview, children were given control to discuss any event( $s$ ) they chose; in the second half; interviewers indicated a change in topic and raised one of the issues that had to be addressed. Open-ended questions were then used to elicit information about each issue”. - Kim Roberts, Canada

"Several agencies within Salt Lake County participated in a study with Michael Lamb and his colleagues at NICHD from 1997-2000. The results were so convincing and the forensic interviews improved so dramatically that the Children's Justice Center developed a training curriculum in 2001. While the curriculum includes many topics, the NICHD Protocol is exclusively taught as the method for conducting forensic interviews of child victims and witnesses." - Heather Stewart, USA

"Use of one systematic tool nationwide for investigating all alleged victims, witnesses and suspects permitted us to perform descriptive studies as well as revealing field experiments. Interestingly, comparing reports made by alleged victims to those made by young suspects and witnesses in corresponding cases, all conducted with the NICHD Protocol, allowed a measure of accuracy of the allegations obtained with the Protocol and further validated the Protocol (Hershkowitz, Fisher, Lamb, \& Horowitz, 2007). The value of specific strategies included in the Protocol, such as rapport-building (Hershkowitz, 2009), open-ended questioning (Hershkowitz, 2001) or facilitative techniques (Hershkowitz, Orbach, Lamb, Sternberg, \& Horowitz, 2002) has also been demonstrated in separate studies. ” - Irit Hershkowitz, Israel

The NICHD Protocol has, at its core, developmentally-appropriate expectations about children's capabilities, and seeks to maximize the conditions in which children are most likely to describe their experiences of abuse accurately. The use of open-prompts is strongly emphasized, because, as discussed, they are more likely to elicit detailed and accurate information.

What makes the approach taken by the developers of the NICHD Protocol so unique is that they sought to create forensic interviewing guidelines that clearly specified the types of interviewer prompts that were appropriate to use in interviews with children, while at the same time 
restricting opportunities for interviewers to fall into the 'suggestibility trap' by asking focused questions based on their own assumptions about things that might have happened. The goal was to create an interview Protocol that could be used by interviewers around the world with varying levels of experience and training, and, importantly, that could be used by interviewers who did not have highly specialized knowledge of suggestibility research and memory development.

Moreover, the NICHD Protocol also was developed to be robust enough to withstand legal challenge. The solution lay in providing not only guidance regarding general concepts about memory and suggestibility, but also specific and structured guidance about exactly the sorts of things that should be said, and in what order. The advantage of this structured approach was that it promised to level the playing field by providing all children with equal opportunities to recount their experiences regardless of individual interviewer biases and pre-existing beliefs about children's capabilities and case similarities (see Table 1).

[Insert Table 1 about here]

The Protocol covers all stages of the investigative interview. The introductory phase was influenced by various law enforcement agencies in different jurisdictions who requested the inclusion of questions designed to establish that children understood the difference between true and false statements in anticipation of legal challenges to children's credibility. Interestingly, use of the Protocol in general has been shown to improve assessments of credibility:

"Research conducted in Israel stressed that use of the Protocol positively affects not just the quality of interviewers' questioning and children's statements but also improves the ability of professionals to distinguish between plausible and implausible statements and assess the statement's credibility (Hershkowitz et al, 2007).”- Irit Hershkowitz, Israel.

In the introductory and ground rules phase interviewers tell children that they should tell the truth and that they will be required to describe events in detail because the interviewer was not present and therefore does not know what has happened. Children are also instructed to say, 
"I don't remember" or "I don't know" when unsure. Both conveying interviewer naiveté and giving the child permission to say "I don't know" have positive effects on error reduction in lab events (e.g., Gee, Gregory \& Pipe, 1999; Mulder \& Vrij, 1996). Children are also told to say "I don't understand", when they do not understand what the interviewer is saying. This initial phase is designed to remove potential pressure that could manifest itself as suggestive influence later in the interview should the children feel that they must acquiesce to leading questions or suggestive utterances. These ground rules can also serve as a form of protection for the interviewer when, as invariably happens, a suggestive or leading question is inadvertently asked. The number and type of ground rules used can differ across jurisdictions due to legal requirements, and the Protocol is flexible enough to allow such variation.

"In Utah, there have been a few revisions made to the NICHD Protocol since we began training it in 2001 due in part to courtroom experiences. For example, here in Salt Lake City, the Protocol is referred to as the NICHD investigative interview guidelines. The term Protocol has been misused, overstated and exaggerated within local courts. Interviewers were unfairly and inaccurately criticized for conducting improper interviews when others erroneously stated that because interviewers failed to ask every question, they did not "follow Protocol". Other revisions consist of the addition of two new ground rules including eliciting a promise to tell the truth." - Heather Stewart, USA

Interviewers sometimes perceive the ground rules as an optional-extra, and run through them at the start of the interview as if they were a 'litany'. Doing this in a monotonous voice, or if treated as an unimportant or unnecessary, can obviously be distancing and rapport-suppressing, if not a strange experience for the child. However, there are sound reasons for including them at the start of an interview and interviewers should try to go through them in a child-friendly manner. Communication of the ground rules allows children to be made aware that they are in control of the interview and that they can ask interviewers to explain anything that they do not understand. It makes complete sense to set out the ground rules at the start of the interview, rather than during the interview (i.e., as was recommended in the Cornerhouse Forensic 
Interview Protocol; see Anderson et al., 2010); it is inappropriate to tell children that they should not guess and say "I don't know" after they have already recounted an experience of child abuse. Further, training in the Ground Rules phase is legally more preferable than deliberately making mistakes when discussing the allegation.

Interviewers then create a relaxed, supportive environment while trying to gauge the children's social and emotional needs. Building and maintaining rapport can be critical to the child's willingness to talk in the interview, and is further extended during what is known as the Practice Interview (see Roberts, Brubacher, Powell \& Price, 2011 for a review).

"We explored the dynamics of the child-interviewer interaction in substantiated cases of abuse (Hershkowitz, Orbach, Lamb, Sternberg, Pipe, \& Horowitz, 2006) and learned that those who disclosed abuse were provided with facilitating and supportive questioning which increased their cooperation, while those who refrained from disclosing were provided with more intrusive and non-supportive interviewing which made them more reluctant. Interestingly, children's reluctance was signalled early in the interview, both by verbal and nonverbal means (Katz, Hershkowitz, Malloy, Lamb, Atabaki, \& Spindler, 2012)”. - Irit Hershkowitz

In the practice interview, children are prompted to describe a real episodic experience in detail in response to open-prompts. Interviewers can sometimes pre-plan suitable events to discuss by talking to parents and guardians or can elicit events from children during the rapportbuilding phase (e.g., "tell me about the things you like to do" followed up with prompts about a specific time the child engaged in that activity). This phase allows interviewers to introduce the kinds of prompts that will be used when the events of interest are later discussed, thereby demonstrating to the children the level of detail required, and the fact that interviewers are naïve or ignorant regarding the children's experiences. The significance of this phase is that it also focuses children on actual events because they are asked to provide specific details about things that really happened - not things that they, for example, have been told to say by others. Importantly, the Protocol from the outset moves conversation away from topics and activities 
that could facilitate suggestibility and foster fantasy, such as including discussions of movies, stories, imaginary friends, as well as drawings and opportunities to play with toys.

"In English-speaking Canada, interviewers are also encouraged, depending on time, to ask about another time children were involved in the same event. This provides awareness and practice in recalling individual episodes of a repeated event in detail." - Kim Roberts, Canada

The transition between the introductory, rapport-building, and practice narrative phases (collectively, the pre-substantive phase) and the substantive phase of the interview is important. In the transition phase, a series of prompts are used to identify the target event/s under investigation as non-suggestively as possible. Because suggestive questions are defined as any information introduced by the interviewer that has not already been mentioned by the child, the interviewer cannot be the first to raise the topic. Hence, in an effort to be non-suggestive the interviewer should simply ask the child if they know why they are being interviewed, and if so, the interviewer should try to obtain an account by using an open-prompt such as "tell me what happened", followed by further open prompting (see Orbach \& Pipe, 2011, for further details).

Sometimes, however, children do not provide any information to the interviewer's initial prompt "tell me why you came to see me today". In such cases, the interviewer needs to needs to ask another question; according to Sternberg, Lamb, Orbach, Esplin, and Mitchell (2001) more than four-fifths of the children who make allegations do so in response to a completely open prompt. For this reason, interviewers should always allow children to raise the topic themselves. If children do not make allegations and the investigators have good reason to suspect that they were indeed abused, however, the interviewer may need to move on to use a series of increasingly focused prompts, perhaps including a prompt like "your teacher told me that you said someone has touched your privates. Tell me about that". This prompt is suggestive because it refers to information that the child has not told the investigator, so should be used only if 
necessary, and in such a way as to focus attention without identifying the alleged perpetrator, the location, or other details about the suspected incidents. If the child agrees with the investigator's assertion, it is crucial that the investigator resume using open-ended prompts, starting with: "So someone touched your privates. Tell me everything about that." Open-ended prompts like this allow the child to report details not suggested by the investigator, and return control to the child. As noted above, some children do not make allegations in response to such prompts when they are first given the opportunity to do so, and investigators should always consider whether it would be best to abort the interview rather than ask contaminating suggestive questions. Of course, when there are child protection concerns, it is often necessary to proceed with caution, despite the attendant risks. New research has also focused on revising the protocol to include supportive and facilitative strategies for approaching reluctant children.

"The Revised Protocol was recently tested in Israel in two different studies and was found effective in reducing children's reluctance and increasing their responsiveness (Hershkowitz et al., in preparation a) and consequently, in facilitating disclosure of abuse (Hershkowitz et al., in preparation $b$ ). The validation of the Revised Protocol opened the way for its implementation nationwide." - Irit Hershkowitz, Israel

When children do make allegations, interviewers are encouraged to elicit further information using additional open-prompts such as "then what happened," "tell me more about that," and "you said X, tell me more about that," for example. Once the child has provided an initial account it is sometimes necessary to ask whether the abuse occurred "one time or more than one time" in order to clarify the components of specific incidents. While not an open-ended prompt, this format is recommended when asking about frequency because children have difficulty estimating a specific number of occurrences (Sharman, Powell, \& Roberts, 2011; Wandrey, Lyon, Quas \& Friedman, 2012), and reduces the risk that an inaccurate specific number could hurt credibility. Research showing the difficulty children (and adults) have with 
source monitoring has influenced the expectations we should have about the number of separate incidents that interviewers can hope children will describe accurately (for further research on children's ability to describe specific occurrences of repeated events, see Powell, Thomson, \& Dietze, 1997; Roberts \& Powell, 2001, for reviews). Interviewers are encouraged to focus on the times that are likely to be the best remembered - the first time, the last time, and another time (Lamb et al., 2007; www.nichdprotocol.com).

After children have provided sufficiently detailed narrative accounts, interviewers may want to consider taking a break, if requested by the child or if the interviewer wants to check with those observing the interview (unobtrusively) if further or more detailed information is required. For example, in Norway, interviews with suspected child sexual abuse victims are conducted at a Statens Barnehus (Child Advocacy Centre) and the 'break' is used to consult with the judge (sometimes more than once).

"The interview is conducted in specially-designed video interview suite, whilst the judge, prosecution, defense lawyers and state-funded counsel to the complainant observe the interview in an adjoining monitor room via video link. The interview process and the presence of observers in the monitor room are normally explained to children in developmentally-appropriate terms. Once the interviewer has elicited an account from the child, he/she takes a break to consult counsel and the judge, leaving the camera running. The judge gives both parties the opportunity to suggest topics or identify contradictions that they want investigated. The interviewer then returns to the interview room to address these issues and then consults the observers again. This process continues until the judge and counsel are satisfied. The child then leaves the interview room, meets his/her guardian and the interview is finished. The video replaces the need for the child to attend or testify in open court, provide evidence or be cross-examined. In other words, the child's involvement in the judicial process almost always comes to an end after the interview, even if the case is appealed." - Trond Myklebust, Norway

After the break interviewers can ask focused questions to explore important details that may be missing. Because memory and many other cognitive skills develop over time and younger children can be less informative than older children about their experiences, preschoolaged children may require more focused questions than older children: 
"Because child investigators showed special difficulties interviewing pre-schoolers, one study focused on young children's responsiveness to the NICHD Protocol, making clear that even very young children can benefit from Protocol guided interviews while stressing that some strategies employed in the Protocol (e.g., asking focused questions paired with open-ended follow-up prompts) are more effective than others in evoking elaborated statements from young children (Hershkowitz, Lamb, Orbach, Katz, \& Horowitz, 2012)." - Irit Hershkowitz, Israel

Focused questions of the wh-/how variety are preferable to yes/no questions (e.g., "was it A or B?") or those providing choices because wh-/how questions do not include a possible response within the question, as opposed to closed questions. Questions containing options may mislead children, causing them to acquiesce to non-experienced events and details suggested by the interviewer (Bruck et al., 1995; Pipe, Sutherland, Webster, Jones, \& La Rooy, 2004; Poole \& Lindsay, 1995). Hence, it is particularly important that interviewers only ask these questions when absolutely necessary, and that they follow up with open-ended questions that transfer control back to the child and minimise contamination (e.g., "So it hurt. Tell me everything about that").

Suggestive utterances, which strongly communicate desired responses, are discouraged by the NICHD Protocol. Research conducted in the last decade has shown clearly how dangerous such questions can be, and most professionals agree that there has been a general decline in the frequency with which such questions are used. Several studies show that the number of suggestive questions asked in forensic interviews is actually quite low (e.g., <10\%; Cederborg et al., 2008; Orbach, Hershkowitz, Lamb, Sternberg, Esplin, \& Horowitz, 2000; Sternberg et al., 2001).

Close to termination of the interview, children are asked how others came to find out about the abuse, because doing so may have the benefit of producing new investigative leads (Orbach \& Pipe, 2011). Finally, children are invited to ask any questions they may have of the 
interviewer, given contact information should they wish to speak with the interviewer again, and the interview is closed on a neutral topic (www.nichdprotocol.com).

Using a standardized approach to interviewing has important advantages that go beyond simply conducting superior interviews. A standardized approach gives all children who are interviewed an equal opportunity to disclose or not disclose alleged abuse. Personal biases such as underestimating children's capabilities, or those resulting from certain case characteristics, are minimized.

"The NICHD Protocol was initially tested and implemented in Israel in 1996, and its development has strongly affected the practice of child investigation in Israel since. The first and partial version scripting only the pre-substantive part of the interview was implemented and tested by Sternberg et al. (1997) in Israel following unfruitful efforts to train the interviewers to conduct appropriate interviews. This study evoked the first insight that a structured Protocol rather than general guidelines can lead to better organized questioning and that children are very responsive when the rapport-building is structured, providing remarkably more forensic information in their first spontaneous statement." - Irit Hershkowitz, Israel

"First training was conducted on the translation of a guideline on forensic interviewing in 2008, however the translated NICHD Protocol was soon thereafter introduced in 2009.

Professional opinion in Japan recognized the similarity of the core concepts in both the guideline and the NICHD Protocol, but the protocol was preferred due to the fact that it is more structured with specific words and phrases suggested for interviewers to use. Each year, two groups of 12 social workers and psychologists working at Child Guidance Centers in Hokkaido attend four days of NICHD protocol training. Since 2010, training is provided in other areas of Japan as well. Also, police officers, prosecutors, and family court investigators attend the course at Hokkaido University. So far, more than 1000 professionals have been trained on the NICHD Protocol." - Makiko Naka, Japan

\section{Training child forensic interviewers}

Initial training should be intensive and last for 5 to 10 days. The content of the training should include discussion of the importance of forensic interviews with children, the fact that children can be reliable witnesses, and the role of the investigative interviewer in promoting the well being of children in the forensic context. Interviewers also need to know some of the basic concepts of child development particularly relating to memory, language, time, touch, attention, 
social skills and cognitive abilities. Interviewers do not necessarily need to become 'experts' during the training but should at least have a basic understanding of children's abilities in the context of child interviewing. It is also worth raising awareness of key studies that are described in the literature so interviewers can get a flavour of the science behind many of the recommendations, which in turn will prepare them to defend their interviewing practices in court if challenged by defense counsel.

"In addition to police officers conducting the interviews in Finland, there are five University Hospital units specialized in assessing allegations of CSA. The staff consists of psychologists specialized in child forensic interviewing as well as medical doctors and social workers (and nurses with a degree in family therapy). According to national guidelines (Finnish Medical Society Duodecim, 2006; Ministry of Social Affairs and Health, 2009), the child interviewers should be familiar with developmental as well as forensic psychology. Interviewers, both within the police force and within the specialized hospital units, are recommended to use the NICHD interviewing Protocol, and interviews are always recorded and transcribed word for word. The recorded interviews are watched in court and thus replace the hearing of the child in person." - Julia Korkman \& Anu Aromäki-Stratos, Finland.

"Each province in Canada has significant control over how training of detectives in child interviewing is conducted. Since 2005, detectives in Ontario (the most populated province) attend a two-week course on Interviewing Offences Against Children at the Ontario Police College. Currently, only two to three days of this course is focused on child interviewing. Because of the issue with knowledge vs. practice, and because of a deep-seated belief of me and the Course Instructor that child interviewing is an expert skill on par with polygraph training, we are now moving to two separate courses - one that covers offenses (e.g., human trafficking) and one that is focused exclusively on child interviewing. The new Child Interviewing course will provide extensive practice and feedback on adherence to a NICHD-style Protocol. Given that around 800 detectives have been trained since 2005, we are confident that this new course will result in significant improvements in the quality of interviews." - Kim Roberts, Canada

Beyond knowledge of children's developmental capabilities, interviewers also must understand the different components of a best practice interview: ground rules, rapport building, the practice interview, and questioning children about substantive issues using different kinds of techniques, with a focus on appropriate interviewer prompts and eliciting narrative information about what happened during the event(s). This is the core of the initial training. The trainers should discuss each one of these parts, including a detailed rationale of its importance using 
current studies (e.g., evidence from lab and field studies supporting the use of open- ended prompts to elicit narratives).

"Since 2008, a full week of training in the NICHD Protocol is offered to police officers as part of a four-week training program on child maltreatment investigation. The NICHD Protocol training includes a review of knowledge on child's memory, suggestibility, children's language and development, as well as a detailed explanation of the structure and use of the NICHD Protocol and discrimination of type of questions. For new investigators, the NICHD Protocol is perceived as helpful and reassuring." - Mireille Cyr, Canada

"Since 2009, there is a training programme in Finland for child forensic interviewers both from within the police force and from the university hospital units. The training includes 10 days of theory about children's development, particularly concerning memory, language and suggestibility, decision making, beliefs and attitudes and the impact of these, and studies of child interviews using the NICHD protocol as well as supervision in small groups where interviews made by each participant are watched and analysed. Trainees also are requested to hand in selfevaluated interviews. A study concerning the impact of the training is presently being undertaken. One clear challenge is that only a very limited number of police officers are trained each year, implying that a large share of the forensic child interviews in Finland are still being done by virtually untrained police officers, as the training in forensic child interviewing within the police academy curricula is modest." - Julia Korkman \& Anu Aromäki-Stratos, Finland

"In the training, there were some difficulties that were similar to those encountered elsewhere. For instance, trainees easily confused forensic interviews with counseling or therapy, probably due to the high value of empathy and social support. There were also some difficulties in training interviewers on the importance of eliciting narratives, which may reflect personal beliefs and practices surrounding adult-child conversation. Importantly, these problems were met with modification of training rather than changing the Protocol, highlighting the absolute importance of continual monitoring of standards. " - Makiko Naka, Japan

After this introduction, the trainers should expose the interviewers to real NICHD Protocol interviews (preferably via video tape but a transcript can be useful as well) that present questions, dilemmas and difficulties concerning the discussed issues. Finally, exercises in role playing for all the participants should take place; these should be followed by detailed feedback from the group members and at the end by the trainer. Trainers should also have a way of recognizing good interviewers who demonstrate an adherence to best practice guidelines.

"Initial training includes extensive role play so that trainees can practice conducting mock interviews using the NICHD Protocol. This allows participants to receive feedback in a non-threatening, supportive environment before conducting interviews on real cases. The result 
is decreased anxiety and increased confidence. Introducing participants to feedback during their initial forensic interview training program helps to normalize the process. This ensures that future feedback is expected and welcomed." - Heather Stewart, USA

"Videotaped interviews conducted with real victims are used to show good practice with the Protocol, and examples of challenges and difficulties typically faced with children at different ages. The training also includes practice in small groups of four police officers with actors playing script roles of children. These practices are videotaped and discussed in the small group afterwards. Feedback includes both the respect for the structure and steps of the Protocol, as well as alternative open-ended questions (invitations) that could have been used to obtain the desired information and interviewer behaviors and attitudes towards the victim. The supervision of these practices is done alternatively during the week by a team made up of psychologists or social workers and police officers. A practical exam is done at the end of the week in order to certify the training." - Mireille Cyr, Canada

"Evaluation studies of training were conducted in 2008, 2009, and 2010, analyzing the mock interviews conducted by trainees before and after the training. It was expected that training would increase the amount of interviewee utterances while decreasing interviewer utterances. Although improvements were not evident initially, we found that by emphasizing the importance of following the NICHD Protocol, enhancing and practicing the use of open-ended questions, and repeating role plays with review and feedback (i.e., videotape role plays and review them in a group) at least three to four times, it was possible to further improve standards to acceptable levels. The analysis of the most recent sample obtained in 2010 showed interviewers used more open-ended questions and less focused questions in the post-than in preinterviews, which resulted in the increase of information provided by the interviewees (Naka, 2011). Although there is a long way to go until full implementation of the NICHD Protocol in the legal system, according to a survey by Yamamoto (2012), the number of Child Guidance Centers utilizing the protocol increased 12 out of 144 in 2007 to 65 out of 146 in 2010. " - Makiko Naka, Japan

It is also important that police trainers are experienced forensic interviewers who can share their experiences concerning the importance of using the guidelines and the challenges of presenting their work in the legal context. Ideally, experienced prosecutors should provide guidance about specific legal requirements with viewpoints of experts for the defense also considered.

"The regulations and guidelines in Norway state that investigative interviews of children should only be conducted by qualified interviewers who had been specially trained. Assuming that specially trained police officers would elicit more information from children than officers without such training, they are provided substantial resources in conducting these interviews. All police officers in Norway complete a three-year bachelor's degree at the Norwegian Police University College (NPUC) before beginning patrol work at investigation units, or embarking on 
further specialised training also available at NPUC, including use of structured interview models influenced by the NICHD protocol research.. The child interviewers are the most qualified interviewers in Norway and have dedicated most of their professional careers to investigative interviews of children." - Trond Myklebust, Norway

Being in possession of the NICHD Protocol, and using it to provide desirable structure to interviews does not require huge organizational changes or expense. The NICHD Protocol does not contradict the key recommendations of other published interview guidelines and the NICHD Protocol can be easily incorporated into existing training.

"It is hard not to use the NICHD Protocol as it incorporates so many of the internationally accepted guidelines! An attractive feature of the NICHD Protocol in Canada (see comments by Mireille Cyr regarding Quebec, where the legal system differs from the remainder of the country) is that it can be adapted to include different jurisdictional practices. In Canada, as in some other countries, Judges no longer give child witnesses a competency test to determine if they know the difference between the truth and lying. This makes the use of the 'Truth/Lie Ceremony' at the beginning of the investigative interview especially important. It is the only time in the course of an investigation where children are asked to promise to tell the truth. Further, the video-recorded interview can be used as evidence-in chief and the promise can bolster children's credibility." - Kim Roberts, Canada

"Providing this highly specialized and intensive training is very cost effective. Once local experts and representatives of crucial disciplines are identified, they are cultivated as trainers. In some cases, there is no extra fee required for trainers as they provide forensic interview training within their scope of work. In other cases, trainers are employed on a contracted basis. The cost of training materials is nominal and many have access to free training space. It is at the discretion of the sponsoring agency to provide snacks and lunches." Heather Stewart, USA

\section{Providing training for interviewers}

It is absolutely crucial, however, to understand that NICHD Protocol interview training must be accompanied with ongoing feedback. Initial training programs that do not dovetail with ongoing feedback for interviewers are not sufficient at improving investigative interviewing in the long term (Lamb et al., 2002a; Powell, 2008).

"During the studies and implementation of the Protocol in Israel, we realized that systematic training and ongoing supervision was critical in order to establish and maintain the interviewers' skills (Lamb et al., 2002a; 2002b).”- Irit Hershkowitz, Israel 
"As research shows practice and feedback are necessary for the maintenance of skills (Lamb et al., 2008); we are now providing continual training, feedback and support for interviewers in many locations in Japan." - Makiko Naka, Japan

Most jurisdictions, for a variety of reasons, do not provide interviewers the support and feedback that they need which can result in disastrous consequences when they are taken to task about the quality of their interviews (La Rooy \& Halley, 2010).

"Without feedback, interviewers can make the inaccurate judgment that the Protocol "doesn't work". Interviewers believe that they are following the Protocol but it is only when systematic feedback is given that they realize how little they have actually used the Protocol." Kim Roberts, Canada

Research has shown that ongoing training that provides continuous feedback beyond initial training sessions is effective at maintaining high standards (Lamb et al., 2002a; Lamb et al., 2002b). These studies showed that interviewers who were provided with initial training on how to use the NICHD Protocol, followed by ongoing group and individual training and feedback, conducted interviews containing higher proportions of open-prompts and lower proportions of option-posing and suggestive utterances; however, when the training and ongoing supervision stopped, there was a decline in the proportion of open-prompts used and an increase in the proportion of more risky option-posing questions. Effective training, therefore, begins with introducing interviewers to the structured NICHD Protocol followed by intensive and systematic training that provides ongoing individual and group supervision and feedback.

"Initial training, however intensive, is not enough to maintain the quality of interview practices. Therefore, the training program is continuous and ongoing and both informal and formal approaches are implemented. For example, when conducting forensic interviews on actual cases feedback is provided during the interview break(s) and again during the debriefing process immediately following each interview. Forensic interviews are always viewed during team case review meetings. In a more formal and standardized process, feedback is provided to interviewers during regularly scheduled peer review sessions. During all mechanisms of feedback, both positive and negative interviewer behavior is addressed and recommendations provided." - Heather Stewart, USA 
"Following training with child protection workers in Ottawa, the workers initiated 'lunch labs' where they could meet informally and focus on a particular issue of interviewing children. This complemented the feedback provided by researchers on NICHD Protocol-based interviews and illustrates how the trained can themselves become the trainers." - Kim Roberts, Canada

In most cases, experienced interviewers can provide follow-up training and feedback to less experienced interviewers. And, due to the structured guidelines of the protocol, well-trained interviewers could potentially reflect on the quality of their own interviews at regular intervals.

In Quebec, Canada, there are some police departments with only one interviewer, posing a challenge for external feedback:

"Feedback and supervision of interviews with real children after the week of training remains a challenge, because the school of police does not have the resources to offer it. Although trained investigators who worked in the same office could help each other with the use of the Protocol, most police officers are the only trained person to interview children in some areas of Quebec. Consequently, they do not benefit from the support of colleagues. This issue of post-training support and feedback remains important as, in a recent study, we have shown that without feedback after the week of training, investigators using the NICHD Protocol asked more open-ended questions than before training but less than police officers who received ongoing feedback. Feedback on real interviews helps increase the number of open-ended questions, as well as the number of details obtained (Cyr, Dion, McDuff, \& Trotier-Sylvain, 2012)." - Mireille Cyr, Canada

\section{Adopting the NICHD protocol when legal system requirements may pose a challenge}

All of the experts who have provided commentary on the use of the NICHD protocol throughout this review work in countries where the legal system already encourages high-quality interviewing of child victim/witnesses, or where recent changes have taken place to facilitate the transition to incorporating the Protocol. In this last section, we highlight the adoption of the NICHD protocol in Portugal which is slowly seeing improvements to its legal system with regards to child interviewing:

"Portugal is embarking on the first steps to establish evidence-based forensic interviewing. Children are currently forced to make several formal statements (to child protection services, police, prosecutor's office, forensic assessment, judge) even though they do 
not have a proof statute (in Portuguese law the proofs that are used to make a judicial final decision are the ones that come up during trial). Ribeiro (2009) found that suspected victims of sexual abuse had to make around eight statements from the initial complaint (usually at the police station) to the trial. Peixoto (2012) also showed, even in cases where physical and biological signs of abuse existed, children were forced to repeat the same statement four to nine times.

In 2007, protecting children's statements in child sexual abuse cases became mandatory. Children, after criminal investigation, are interviewed by a judge to prevent them from having to testify in court. In this judicial procedure, called "declarações para memória futura" (DMF; "statement for future use"), the prosecutor and the defence lawyer have a mandatory presence and can cross-examine the witness. Also, the presence of a psychologist to support the child is mandatory, but the law does not explain exactly what kind of support is required or exactly what role of the psychologist is appropriate. DMF does not prevent children being interviewed numerous times during the criminal investigation, despite being the only formal interviewing with proof statutes because a judge manages it. Even the objective of DMF on preventing children's appearance in the trial is often not accomplished, and they are called upon to testify there. Portuguese judges currently do not have proper training in child interviewing and do not use any standardised forensic interview procedure. Also, interviews are not video recorded, and sometimes interviews are recorded only as handwritten statements. So, while Portuguese Law acknowledges the importance of procedures that ensure that children's statements are protected, and the desirability of spontaneous children's testimony is also acknowledged, the proper conditions to maximise opportunities for children to provide testimony do not as yet exist. 
The implementation of the NICHD Investigative Interview Protocol can have a strong impact on the quality of interviews conducted, as well as on the number of cases brought before courts (Pipe, Orbach, Lamb, Abbott, \& Stewart, 2013). Thus, we have initiated a translation of the NICHD Protocol to Portuguese language and judicial context. The process was planned in four steps: translation; linguistic and cognitive review; applicability; and legal usefulness. Translation was carried out by three independent translators. Then the three translations were integrated to a final translation. Next we checked that the translated verbatim text in fact accessed the cognitive processes that we intended to prompt. Our main concern was about the translation of the expression "tell me", that in Portuguese can have several translations. The more intuitive translation ("conta-me") has semantic proximity to a word that is associated with fantasy and fairy tales stories ("conto"). So, we tested which was the best expression to use in Portuguese comparing three that we thought to be the closest match: "conta-me", "fala-me", “diz-me" (Peixoto, Alberto \& Ribeiro, 2011). Children $(N=109)$ aged 4- to 15-years old watched a video and then were prompted to recount the video using the three translation suggestions to "tell me". Data suggested that "conta-me", despite our previous worries, was the expression that prompted fewer errors and suppositions.

After reaching a final interview protocol document we initiated the full application of the NICHD Protocol in real cases. We are now collecting data to observe whether the Portuguese version has similar results to other versions of the Protocol. The next step is to evaluate the degree of improvement that the use of the Protocol can bring to the Portuguese judicial procedures; as such, we are also collecting formal interviews done on DMF to show actual quality of interviews being done. We expect to show a substantial improvement in children's interviews with the NICHD Protocol, increasing quantity and quality of information. 
To fully gain the benefits associated with this kind of forensic interview Protocol, new changes must be made in the Portuguese procedural legal code (e.g., mandatory use of a forensic interview protocol, mandatory video recording of interviews). In March 2012, Portuguese Parliament approved a resolution that ratifies the 2007 European Council Convention for Children's Protection Against Sexual Exploitation and Sexual Abuse. The European Council Convention defends in article 35 that children's statements should be obtained as briefly as possible, in child-friendly premises, with interviews performed by specialised professionals, and if repeated, by the same person." - Carlos Peixoto, Portugal

\section{Conclusions}

In summary, our understanding of the issues surrounding the forensic interviewing of children have helped shape many professional recommendations internationally. Because our knowledge of memory and suggestibility is now so advanced, core recommendations made by professional bodies worldwide reveal remarkable consensus and are unlikely to change dramatically. The NICHD protocol encompasses this body of knowledge and reflects these international recommendations, and was developed from a sound theoretical and empirical research base through the dedicated work of experts invested in improving the welfare of children worldwide. The full protocol, which is freely available, can be found at www.nichdprotocol.com in a variety of languages.

The forensic interview plays a crucial role in the context of child abuse investigations and it often determines how the rest of the investigation progresses. Consequently, proper training of forensic interviewers is paramount. Forensic interviewers should receive training in methods that have scientific backing and proven efficacy and we therefore recommend empirical evaluated structured interview models, such as the NICHD Protocol, to be employed as a training tool 
wherever possible. Initial training must always be accompanied by continuous ongoing training and support. In order for this approach to be successful, it must be supported by all those involved in child interviewing from the front line interviewers, to administrators and managers, and government officials that mandate guidelines. If forensic interviewers are expected to do such important work, they need to be properly equipped with the support and tools necessary to be successful. We believe that the NICHD protocol, based upon a solid foundation of scientific research and validated in many countries around the world, can provide exactly that support to those involved in the critically important role of front-line investigative interviewers of child victims and witnesses. 


\section{References}

Aldridge, J., \& Cameron, S. (1999). Interviewing child witnesses: Questioning techniques and the role of training. Applied Developmental Science. Special Issues: New Research on child witnesses: Part II, 3, 136-147. doi: 10.1207/s1532480xads0302_7

American Professional Society on the Abuse of Children (1990). Guidelines for psychosocial evaluation of suspected sexual abuse in young children. Chicago, IL: Author.

American Professional Society on the Abuse of Children (1997). Guidelines for psychosocial evaluation of suspected sexual abuse in young children (Revised). Chicago, IL: Author.

Anderson, J., Ellefson, J., Lashley, J., Miller, A.L., Olinger, S., Russell, A., ... Weigman, J. (2010). The Cornerhouse forensic interview protocol: RATAC. Thomas M. Cooley Journal of Practical \& Clinical Law, 12, 193 - 331.

Bass, E. \& Davis, L. (1988). The courage to heal: A guide for women survivors of child sexual abuse. New York, USA: Harper \& Row Publishers.

Bauer, P. J., Wenner, J. A., Dropik, P. L., \& Wewerka, S. S. (2000). Parameters of remembering and forgetting in the transition from infancy to early childhood. Monographs of the Society for Research in Child Development, 65 (4, Serial No. 263).

Black, R. (1992). Orkney A Place of Safety?. Edinburgh, UK: Canongate Press.

Brainerd, C.J., \& Reyna, V.F. (2005). The science of false memory. Oxford, UK: Oxford University Press.

Bruck, M., Ceci, S. J., Francoeur, E., \& Renick, A. (1995). Anatomically detailed dolls do not facilitate pre-schoolers' reports of a paediatric examination involving genital touch. Journal of Experimental Psychology: Applied, 1, 95-109. doi: 10.1037/1076-898X.1.2.95 
Bull, R. (2010). The investigative interviewing of children and other vulnerable witnesses: Psychological research and working/professional practice. Legal and Criminological Psychology, 15, 5-23. doi:10.1348/014466509X440160

Ceci, S. J., Bruck, M., (1995). Jeopardy in the courtroom: A scientific analysis of children's testimony. Washington, D.C., US: APA Books.

Ceci, S. J., Kulkofsky, S., Klemfuss, J. Z., Sweeney, C. D., \& Bruck, M. (2007). Unwarranted assumptions about children's testimonial accuracy. Annual Review of Clinical Psychology, 3, 311-328. doi: 10.1146/annurev.clinpsy.3.022806.091354

Cederborg, A-C., La Rooy, D., \& Lamb, M. E. (2008). Repeated interviews with children who have intellectual disabilities. Journal of Applied Research in Intellectual Disabilities. 21, 103-113. doi: 10.1111/j.1468-3148.2007.00372.x

Clyde, J. J. (1992). The Report of the Inquiry into the Removal of Children from Orkney in February 1991. Edinburgh: HMSO.

Cyr, M., Dion, J., McDuff, P., Trotier-Sylvain, K. (2012). Transfer of skills in the context of non-suggestive investigative interviews: Impact of structured interview protocol and feedback. Applied Cognitive Psychology, 26, 499-660. doi: 10.1002/acp.2822

Cyr, M., \& Lamb, M. (2009). Assessing the effectiveness of the NICHD investigative interview Protocol when interviewing French-speaking alleged victims of child sexual abuse in Quebec. Child Abuse \& Neglect, 257-268. doi: 10.1016/j.chiabu.2008.04.002

Dent, H.R., \& Stephenson, G.M. (1979). An experimental study of the effectiveness of different techniques of questioning child witnesses. British Journal of Social and Clinical Psychology, 18, 41-51. 
Finnish Medical Society Duodecim, Current Care Guidelines. (2006). Lapsen seksuaalisen hyväksikäytön epäilyn tutkiminen. Investigating suspicions of child sexual abuse (in Finnish).

Fivush, R., Gray, J. T., \& Fromhoff, F. A. (1987). Two-year-olds talk about the past. Cognitive Development, 2, 393-409. doi: 10.1016/S0885-2014(87)80015-1

Garven, S., Wood, J. M., Malpass, R. S., \& Shaw, J. S., III. (1998). More than suggestion: The effect of interviewing techniques from the McMartin Preschool case. Journal of Applied Psychology, 83, 347-359. doi: 10.1037/0021-9010.83.3.347

Gee, S., Gregory, M., \& Pipe, M-E. (1999). 'What colour is your pet dinosaur?' The impact of pre-interview training and question type on children's answers. Legal and Criminal Psychology, 4, 111-128. doi: 10.1348/135532599167716

Goodman, G. S., Pipe, M. E., \& McWilliams, K. (2011). Children's eyewitness memory: Methodological Issues. In B. Rosenfeld \& S. Penrod (Eds.), Research methods in forensic psychology (pp. 257-282). New York, US: Wiley.

Hayne, H. (2004). Infant memory development: Implications for childhood amnesia. Developmental Review, 24, 33-73. doi: 10.1016/j.dr.2003.09.007

Hershkowitz, I. (2001). Children's responses to open-ended utterances in investigative interviews. Legal and Criminological Psychology, 6, 49-63. doi: $10.1348 / 135532501168190$

Hershkowitz, I. (2009). Socioemotional factors in child sexual abuse investigations. Child Maltreatment, 14, 172-181. doi: 10.1177/1077559508326224

Hershkowitz, I., Fisher, S., Lamb, M. E., \& Horowitz, D. (2007). Improving the credibility assessment in child sexual abuse allegations: The role of the NICHD investigative 
interview protocol. Child Abuse and Neglect, 31, 99-110. doi:

10.1016/j.chiabu.2006.09.005

Hershkowitz, I., Lamb, M. E., Orbach, Y., Katz, C., \& Horowitz, D. (2012). The development of communicative and narrative skills among preschoolers: Lessons from forensic interviews about child abuse. Child Development, 83, 611-622. DOI: 10.1111/j.14678624.2011.01704.x

Hershkowitz, I., Orbach, Y., Lamb, M. E., Sternberg, K. J., \& Horowitz, D. (2002). A comparison of mental and physical context reinstatement in forensic interviews with alleged victims of sexual abuse. Applied Cognitive Psychology, 16, 429-441. doi: 10.1002/acp.804

Hershkowitz, I., Orbach, Y., Lamb, M.E., Sternberg, K.J., Pipe, M.E., \& Horowitz, D. (2006). Dynamics of forensic interviews with suspected abuse victims who do not disclose abuse. Child Abuse \& Neglect, 30, 753-769. doi: 10.1016/j.chiabu.2005.10.016

Home Office. (1992). Memorandum of good practice on video recorded interviews with child witnesses for criminal proceedings. London, UK: Author.

Home Office. (2002). Achieving best evidence in criminal proceedings: Guidance for vulnerable or intimidated witnesses, including children. London, UK: Author.

Home Office. (2007). Achieving Best Evidence in Criminal Proceedings: Guidance on Interviewing Victims and Witnesses, and Using Special Measures. London, UK: Author.

Hood, L. (2001). A City Possessed: The Christchurch Civic Crèche Case. New Zealand: Longacre. 
Jones, D. P. H., \& Krugman, R. D. (1986). Can a three-year-old child bear witness to her sexual assault and attempted murder? Child Abuse and Neglect, 10, 253-258. doi: 10.1016/01452134(86)90086-4

Katz, C., Hershkowitz, I., Malloy, L. C., Lamb, M. E., Atabaki, A., \& Spindler, S. (2012). Nonverbal behavior of children who disclose or do not disclose child abuse in investigative interviews. Child Abuse \& Neglect, 36, 12-20. doi: 10.1016/j.chiabu.2011.08.006

Korkman, J., Santtila, P., Drzewiecki, T., \& Sandnabba, N.K. (2008). Failing to keep it simple: Language use in child sexual abuse interviews with 3-8-year-old children. Psychology, Crime and Law, 14, 41-60. doi: 10.1080/10683160701368438

Korkman, J., Santtila, P., Westeråker, M., \& Sandnabba, N. K. (2008). Interviewing techniques and follow-up questions in child sexual abuse interviews. European Journal of Developmental Psychology, 5, 108-128. doi: 10.1080/17405620701210460

Korkman, J., Santtila, P., \& Sandnabba, N. K. (2006). Dynamics of verbal interaction between interviewer and child in interviews with alleged victims of child sexual abuse. Scandinavian Journal of Psychology, 47, 109-119. doi: 10.1111/j.14679450.2006.00498.x

Lamb, M. E., Hershkowitz, I., Orbach, Y. \& Esplin, P. W. (2008). Tell me what happened. Chichester, UK: Wiley.

Lamb, M. E., Hershkowitz, I., Sternberg, K. J., Esplin, P. W., Hovav, M., Manor, T., \& Yudilevitch, L. (1996). Effects of investigative utterance types on Israeli children's responses. International Journal of Behavioral Development, 19, 627-637. doi: $10.1080 / 016502596385721$ 
Lamb, M. E., La Rooy, D., Malloy, L. C., \& Katz, C. (Eds.) (2011). Children's testimony: A Handbook of psychological research and forensic practice. Chichester, UK: Wiley.

Lamb, M. E., Orbach, Y., Hershkowitz, I., Esplin, P. W., \& Horowitz, D. (2007). A structured forensic interview protocol improves the quality and the informativeness of investigative interviews with children: A review of research using the NICHD investigative interview Protocol. Child Abuse and Neglect, 31, 1201-1231. doi: 10.1016/j.chiabu.2007.03.021

Lamb, M. E., Orbach, Y., Sternberg, K. J., Aldridge, J., Pearson, S., Stewart, H. L., ., .. \& \& Bowler, L. (2009). Use of a structured investigative protocol enhances the quality of investigative interviews with alleged victims of child sexual abuse in Britain. Applied Cognitive Psychology, 23, 449-467. doi: 10.1002/acp.1489

Lamb, M. E., Sternberg, K. J., Orbach, Y., Esplin, P., \& Mitchell, S. (2002a). Is ongoing feedback necessary to maintain the quality of investigative interviews with allegedly abused children? Applied Developmental Science. 6, 35-41. doi: 10.1207/S1532480XADS0601_04

Lamb, M. E., Sternberg, K. J., Orbach, Y., Hershkowitz, I., Horowitz, D., \& Esplin, P. (2002b). The effects of intensive training and ongoing supervision on the quality of investigative interviews with alleged sex abuse victims. Applied Developmental Science. 6, 114-125. doi: 10.1207/S1532480XADS0603_2

La Rooy, D., \& Halley, J. (2010). The quality of joint investigative interviews with children in Scotland. Scots Law Times, 24, 133-137.

La Rooy, D., Lamb, M. E., \& Memon, A. (2011) Forensic interviews with children in Scotland: A survey of interview practice among police. Journal of Police and Criminal Psychology, 26, 26-34. doi: 10.1007/s11896-010-9072-9 
La Rooy, D., Malloy, L.C., \& Lamb, M.E. (2011). The development of memory in childhood. In M.E. Lamb, D. La Rooy, L.C. Malloy, \& C. Katz (Eds.). Children's testimony: A Handbook of psychological research and forensic practice (pp. 49-68). Chichester, UK: Wiley.

Leichtman, M. D., \& Ceci, S. J. (1995). The effects of stereotypes and suggestions on preschoolers' reports. Developmental Psychology, 31, 568-578. doi: 10.1037/00121649.31.4.568

Loftus, E. F. (2005). Planting misinformation in the human mind: A 30-year investigation of the malleability of memory. Learning \& Memory, 12, 361-366. doi: 10.1101/lm.94705

Ministry of Justice (2011). Achieving Best Evidence in Criminal Proceedings: Guidance on interviewing victims and witnesses, and guidance on using special measures. London, UK: Author.

Ministry of Social Affairs and Health. (2009). Lasten seksuaalisen hyväksikäytön selvittäminen. Työryhmän muistio. Sosiaali- ja terveysministeriönselvityksiä 2009:30. Investigating child sexual abuse (in Finnish). Stable URL: $\underline{\text { www.stm.fi/c/document_library/get_file?folderId=39503\&name=DLFE-9918.pdf }}$

Mulder, M. R. \& Vrij, A. (1996). Explaining conversations rules to children: An intervention study to facilitate children's accurate responses. Child Abuse and Neglect, 10, 623-631. doi: 0.1016/0145-2134(96)00050-6

Myers, J. E. B., (2009). Introduction: Improved forensic interviewing: The legacy of the McMartin Preschool Case. In K. Kuehnle \& M. Connell (Eds.), The Evaluation of Child Sexual Abuse Allegations: A Comprehensive Guide to Assessment and Testimony. (pp. xix-xxv). Hoboken, US: Wiley.

Myklebust, T., \& Bjørklund, R. A. (2006). The effect of long-term training on police officers' use of open and closed questions in field investigative interviews of children (FIIC). 
Journal of Investigative Psychology and Offender Profiling, 3, 165-181. doi:

10.1002/jip.52

Myklebust, T., \& Bjørklund, R.A. (2009). The Child Verbal Competence Effect in court: A comparative study of field investigative interviews of children (FIIC) in child sexual abuse cases. Journal of Investigative Psychology and Offender Profiling, 6, 117-128. doi: 10.1002/jip.97

Naka, M. (2006). Memory talk and testimony in children. In M. Nakayama, R. Mazuka, \& Shirai, Y. (Eds.), Handbook of East Asian Psycholinguistics. (pp. 123-129). Cambridge, UK: Cambridge University Press.

Naka, M. (2011). The effect of forensic interview training based on the NICHD structured protocol. Japanese Journal of Child Abuse and Neglect, 13, 316-325.

Orbach, Y., Hershkowitz, I., Lamb, M.E., Sternberg, K.J., Esplin, P.W., Horowitz, D. (2000). Assessing the value of structured protocols for forensic interviews of alleged child abuse victims. Child Abuse \& Neglect, 24, 733-752. doi: 10.1016/S0145-2134(00)00137-X

Orbach, Y. \& Lamb, M.E. (2001). The relationship between within-interview contradictions and eliciting interview utterances. Child Abuse and Neglect, 25, 323-333. doi: $10.1016 / \mathrm{S} 0145-2134(00) 00254-4$

Orbach, Y., \& Pipe, M-E. (2011). Investigating Substantive Issues. In M. E. Lamb, D. J. La Rooy, L. C. Malloy, \& C. Katz (Eds.), Children's Testimony: A Handbook of Psychological Research and Forensic Practice (pp. 147-163). Chichester, UK: Wiley.

Peterson, C. (2002). Children's long-term memory for autobiographical events. Developmental Review, 22, 370 - 402. doi: 10.1016/S0273-2297(02)00007-2 
Peterson, C. (2012). Children's autobiographical memories across the years: Forensic implications of childhood amnesia and eyewitness memory for stressful events. Developmental Review, 32, 287-306. doi : 10.1016/j.dr.2012.06.002

Peixoto, C. E. (2012). Avaliação da credibilidade de alegações de abuso sexual de crianças: Uma perspectiva psicológica forense [Children's Sexual Abuse Allegations Credibility Assessment: a forensic psychological perspective]. Porto: FPCEUP.

Peixoto, C. E., Alberto, I., \& Ribeiro, C. (2011, May). The Portuguese adaptation of the NICHD forensic interview Protocol: An analysis of some psycholinguistic variables. Presentation at the third IIIRG annual conference, Dundee, Scotland.

Pezdek, K., \& Lam, S. (2007). What research paradigms have cognitive psychologists used to study "False memory," and what are the implications of these choices? Consciousness and Cognition, 16, 2-17. doi: 10.1016/j.concog.2005.06.006

Pipe, M-E., Orbach, Y., Lamb, M. E., Abbott, C. B., \& Stewart, H. (2013). Do case outcomes change when investigative interviewing practices change? Psychology, Public Policy, and Law, 19, 179-190. doi: 10.1037/a0030312

Pipe, M.-E., Sutherland, R., Webster, N., Jones, C. H., \& La Rooy, D. (2004). Do early interviews affect children's long-term recall? Applied Cognitive Psychology, 18, 1-17. doi: $10.1002 /$ acp. 1053

Poole, D. A., \& Lamb, M. E. (1998). Investigative interviews of children: A guide for helping professionals. Washington, DC, US: American Psychological Association.

Poole, D. A. \& Lindsay, D. S. (1995). Interviewing preschoolers: Effects of nonsuggestive techniques, parental coaching, and leading questions of reports of nonexperienced events. Journal of Experimental Child Psychology, 60, 129-154. doi:10.1006/jecp.1995.1035 
Powell, M. B. (2008) Designing effective training programs for investigative interviewers of children, Current Issues in Criminal Justice, 20, 189-208.

Powell, M. B., Thomson, D. M., \& Dietze, P. (1997). Children's ability to remember an occurrence of a repeated event. Expert Evidence, 5, 133-139. doi: 10.1023/A:1008879019605

Price, H. L. \& Roberts, K. P. (2011). The effects of an intensive training and feedback program on police and social workers' investigative interviews of children. Canadian Journal of Behavioural Science, 43, 235-244. doi: 10.1037/a0022541

Quas, J.A., Goodman, G.S., Bidrose, S., Pipe, M.E., Craw, S., \& Ablin, D.S. (1999). Emotion and memory: children`s long-term remembering, forgetting and suggestibility. Journal of Experimental Child Psychology, 72, 235-270. doi: 10.1006/jecp.1999.2491

Quas, J. A., \& Schaaf, J. M. (2002). Children's memories of experienced and nonexperienced events following repeated interviews. Journal of Experimental Child Psychology, 83, 304-338. doi: 10.1016/S0022-0965(02)00150-9

Ribeiro, C. (2009). A criança na justiça: Trajectórias e significados do processo judicial de crianças vítimas de abuso sexual intrafamiliar [The Child and Justice: judicial proceeding's trajectories and meanings to children victims of intra familiar sexual abuse]. Coimbra: Almedina.

Rischke, A., Roberts, K.P., \& Price, H.L. (2011). Using spaced learning principles to translate knowledge into behavior: Evidence from investigative interviews of alleged child abuse victims. Journal of Police and Criminal Psychology, 26, 58-67. doi: 10.1007/s11896010-9073-8 
Ridley, A. M., Gabbert, F., \& La Rooy, D. J. (2013). Suggestibility in Legal Contexts: Psychological Research and Forensic Implications. Chichester, UK: Wiley. Roberts, K. P., Brubacher, S. P., Powell, M. B., \& Price, H. L. (2011). Practice Narratives. In M.E. Lamb, D. La Rooy, C. Katz, \& L.C. Malloy (Eds.), Children's testimony: A Handbook of psychological research and forensic practice (129-146). Chichester, UK: Wiley.

Roberts, K. P., \& Powell, M. B. (2001). Describing individual incidents of sexual abuse: A review of research on the effects of multiple sources of information on children's reports. Child Abuse \& Neglect, 25, 1643-1659. doi: 10.1016/S0145-2134(01)00290-3

Santtila, P., Korkman, J., \& Sandnabba, N.K. (2004). Effects of interviewer phase, repeated interviewing, presence of a support person, and anatomically detailed dolls on child sexual abuse interviews. Psychology, Crime and Law, 10, 21-35. doi: $10.1080 / 1068316021000044365$

Saywitz, K. J., Lyon, T. D., \& Goodman, G. S. (2011). Interviewing Children. In J.E.B. Myers (Ed.), The APSAC handbook on child maltreatment (3d ed.) (pp. 337-360). Newbury Park, US: Sage

Segovia, D. A., \& Crossman, A. M. (2012). Cognition and the child witness: Understanding the impact of cognitive development in forensic contexts. doi: 10.5772/53938Scottish Executive. (2003). Guidance Interviewing Child Witnesses and Victims in Scotland. Edinburgh: Author.

Scottish Executive. (2011). Guidance On Joint Investigative Interviewing Of Child Witnesses In Scotland. Edinburgh: Author. 
Sharman, S. J., Powell, M. B., \& Roberts, K. P. (2011). Children's ability to estimate the frequency of single and repeated events. International Journal of Police Science and Management, 13, 234-242. doi: 10.1350/ijps.2011.13.3.243Sternberg, K.J., Lamb, M.E., Davies, G.M., \& Westcott, H.L. (2001). The Memorandum of Good Practice: Theory versus application. Child Abuse and Neglect 25, 669-681. doi: 10.1016/S01452134(01)00232-0

Sternberg, K. J., Lamb, M. E., Hershkowitz, I., Yudilevitch, L., Orbach, Y., Esplin, P. W., \& Hovav, M. (1997). Effects of introductory style on children's abilities to describe experiences of sexual abuse. Child Abuse and Neglect, 21, 1133-1146. doi: 10.1016/S0145-2134(97)00071-9

Sternberg, K.J., Lamb, M.E., Orbach, Y., Esplin, P.W., \& Mitchell, S. (2001). Use of a structured investigative protocol enhances young children's responses to free-recall prompts in the course of forensic interviews. Journal of Applied Psychology, 86, 9971005. doi: $10.1037 / 0021-9010.86 .5 .997$

Stevenson, K.M., Leung, P., \& Cheung, K.M. (1992). Competency-based evaluation of interviewing skills in child sexual abuse cases. Social Work Research \& Abstracts, 28, $11-16$.

Taskinen, S. (Ed.) (2003). Lapsen seksuaalisen hyväksikäytön ja pahoinpitelyn selvittäminen. Asiantuntijaryhmän suositukset sosiaali-ja terveydenhuollon henkilöstölle. (Investigating Child Sexual Abuse and Assault. The guidelines of group of experts for staff of social welfare and health care.) STAKES. Helsinki. [In Finnish]. 
Wandrey, L., Lyon, T.D., Quas, J.A., \& Friedman, W.F. (2012). Maltreated children's ability to estimate temporal location and numerosity of placement changes and court visits. Psychology, Public Policy, and Law, 18, 79-104. doi: 10.1037/a0024812

Warren, A.R., Woodall, C.E., Thomas, M., Nunno, M., Keeney, J.M., Larson, S.M., \& Stadfeld, J.A. (1999). Assessing the effectiveness of a training program for interviewing child witnesses. Applied Developmental Science, 3, 128-135. doi:

10.1207/s1532480xads0302_6

Yamamoto, T. (2012). Kateinai seibouryoku higaiji (jido gyakutai, jido poruno tou) no hakken, shien ni okeru kaku kankeikikan no taiou to renkei ni kansuru chosa kenkyu. Kodomo Mirai Zaidan. [Survey on actions and cooperation of relevant organizations in finding and supporting the victimized children in intra-familial sexual abuse (child abuse and child pornography]. 
Table 1.

A summary of the stages of the structured NICHD Protocol

1. Introduction

2. Ground rules

- Truth \& lies

- Transfer of control (e.g., "don’t know," “don’t guess," “correct me if I am wrong.”)

3. Rapport (e.g., "what do you like to do? [wait for and answer] Tell me about that.")

4. Practice Interview (Memory training/Cognitive support)

5. Transition to substantive phase

6. Investigate incident(s)

- Open-ended prompts (e.g., "Tell me what happened.”)

- Separation of incidents (e.g., "Did X happen one time, or more than one time?)

[Option to take a Break if necessary]

7. Focused questions about information not already mentioned followed by open-ended prompts

8. Disclosure information (Who did the child initially tell? Who else knows what happened?)

9. Closure (e.g., "Anything else you want to tell," "Do you have any questions to ask me?")

10. Neutral topic (e.g., "What are you going to do when you leave?)

Note. The full version of the NICHD protocol can be found by visiting nichdprotocol.com, along with the adapted 'Ten Step Investigative Interview’ by Lyon, 2005. 